\title{
Effect of the boost pressure on basic operating parameters, exhaust emissions and combustion parameters in a dual-fuel compression ignition engine
}

The dual-fuel engine enables application of various fuels. One of such fuels is propane or its mixture with butane (LPG). Application of such fuels results in reduction of engine operation costs. The paper presents effect of application of such fuel in a turbocharged dualfuel engine on basic operating parameters, exhaust emissions and basic combustion parameters. Test results in the form of load characteristics for various boost ratios obtained for dual-fuel engine were compared to corresponding results obtained for conventional engine operating on diesel fuel only. The obtained results indicate that it is possible a dual-fuel operation with the propane energy share of $70 \%$ for maximum engine loads.

Key words: dual-fuel engine, propane, turbocharging, combustion process, exhaust emission

\section{Introduction}

For many years in the Department of Automobiles and Internal Combustion Engines there are carried out investigations on dual-fuel compression ignition engine operating on various fuels (methanol, ethanol, LPG, propane and natural gas) $[3,6,8,9]$. The majority of tests has been done on an naturally aspirated engine. Because the nowadays applied engines are mostly turbocharged compression ignition engines, authors have made an attempt to analyses the effect of boost pressure on basic parameters describing engine operation and combustion processes.

The tests have been carried out on a comprehensively equipped AVL test stand consisted of:

- single-cylinder compression ignition engine, Tab. 1.

- measurement system for basic operating parameters,

- boost system,

- system for exhaust gas analysis,

- system for combustion parameters registration.

The applied test equipment conforms the following regulations: Directive 1999/96/EC of the European Parliament and of the Council of 13 December 1999, Regulation (EC) No 715/2007 of the European Parliament and of the Council of 20 June 2007 and Commission Regulation (EC) No 692/2008 of 18 July 2008.

Table 1. Main specifications of the AVL 5402 engine

\begin{tabular}{|l|c|}
\hline Number of cylinders & 1 \\
\hline Bore & $85.01 \mathrm{~mm}$ \\
\hline Stroke & $90.00 \mathrm{~mm}$ \\
\hline Displacement & $511.00 \mathrm{~cm}^{3}$ \\
\hline Combustion type & Compression ignition \\
\hline Valve system & $60 \mathrm{deg}$ \\
\hline Valve overlap & 17.5 \\
\hline Compression ratio & $6 \mathrm{~kW}$ \\
\hline Fuelling system & $16 \mathrm{~kW}$ \\
\hline $\begin{array}{l}\text { Maximum effective power, without } \\
\text { supercharging }\end{array}$ & $4200 \mathrm{rpm}$ \\
\hline $\begin{array}{l}\text { Maximum effective power, with super- } \\
\text { charging }\end{array}$ & $180 \mathrm{MPa}$ \\
\hline Rated engine speed & \\
\hline Iniection pressure & Common salem \\
\hline
\end{tabular}

To realize the task formulated in the title of this paper, the engine fuelling system has been modified in such a way to make possible a delivery of gaseous fuel into the intake manifold in a precisely controlled way (in both aspects: amount of fuel dose and correlation between the injection time and timing). The gaseous fuel used in the tests was propane. A schematic diagram of the modified fuelling system is presented in Fig. 1b.
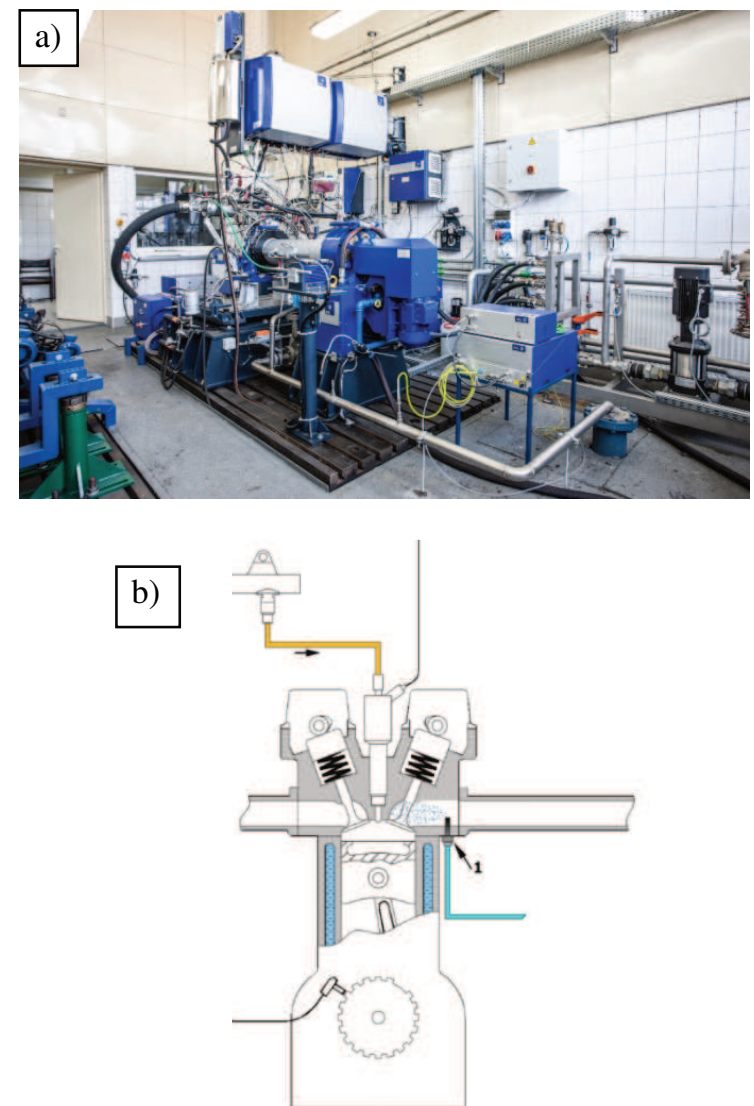

Fig. 1. a) General view of the AVL test bed, b) method of propane delivery into the engine

\section{Investigation procedure}

Commercial solutions based on dual-fuel compression ignition engines operating on gaseous fuels are more and more popular. Due to its well organized distribution network, LPG fuel is often applied in such solutions. The pri- 
mary factor affecting interest in such solution is a competitive price of LPG compared to diesel fuel. The known and not yet very often applied solutions come down to a low LPG energy share (at the loads close to maximum ones, the LPG energy share does not exceed $30 \%$ of the total energy amount delivered by two fuels DF + LPG). Such a low energy share of LPG fuel arises from fear of unexpected negative results like: increase of maximum combustion pressure and increase of maximum and mean values of pressure rise rates [6]. These, generally, simple commercial solutions do not take into account the aspect of exhaust gas composition and changes in thermal and overall efficiencies. Commercial solutions do not apply results of investigations on the selection of diesel fuel dose injection parameters, particularly in modern solution where that dose is divided. Investigation from this field have been carried out in the Department of Automobiles and Internal Combustion Engines. The obtained results have been presented in [9].

The paper presents results of investigation on the effect of the boost pressure on basic operating parameters as well as the main exhaust emissions of a dual-fuel compression ignition engine. In each case, the obtained results have been compared to the corresponding results obtained for the standard version of the compression ignition engine operating on diesel fuel only.

The investigation procedure is based on the following assumptions:

- tests were carried out under conditions for load characteristic preparation at the constant engine speed $\mathrm{n}=$ $1200 \mathrm{rpm}$ for both engine versions (standard operation on diesel fuel and dual-fuel operation on diesel fuel and propane),

- the air excess ratios (total in the case of dual-fuel operation) are comparable at each load point for both engine versions,

- energy share of diesel fuel versus the total energy of both fuels was from the range $25-30 \%$ (depending on the boost pressure from the range 0-400 mbar respectively) in conditions of maximum load,
- limitation of the maximum engine torque (maximum engine load) results from a limitation of the established maximum rate of pressure rise $(\mathrm{dp} / \mathrm{d} \alpha) \leq 10-12 \mathrm{bar} / \mathrm{CA}$, what has been recognized as a safe limit regarding the risk of knocking combustion,

- the boost pressure for both engine versions was equal to 0, 200, 400 mbar,

- standard adjustment of diesel fuel injection parameters in the case of conventionally operating engine for various engine load $\mathrm{T}$ [Nm],

- standard adjustment of injection timing of diesel fuel pilot and main doses in the case of dual-fuel operating engine for various engine load $\mathrm{T}[\mathrm{Nm}]$,

- variable adjustment of the end of injection of the main diesel fuel dose in the case of dual-fuel operating (shortening of the time of injection aimed at a reduction of its quantity with an increase of the propane dose quantity).

\section{Results of investigation on the effect of the boost pressure on the thermal and overall efficiencies and the achieved torque for investigated engine versions}

Keeping the established and described in the 2nd paragraph assumptions, there were prepared load characteristics of thermal and overall efficiencies at the constant engine speed $n=1200 \mathrm{rpm}$. The results are presented in Fig. 2. Analysis of thermal efficiency characteristics obtained for dual-fuel and conventionally operating engines indicates that thermal efficiency of dual-fuel engine is slightly lower for all boost pressure values and engine loads. It is worth to notice, that this unfavorable difference decreases with the engine load. At the maximum load, this difference is very low and do not exceed $1 \%$ (at the minimum load reaching 5\%). Similar trends are observed in the case of engine overall efficiency characteristics. Registered load characteristics of propane concentration in the exhaust gas of dual-fuel engine may be helpful in the interpretation of such trends (Fig. 4).
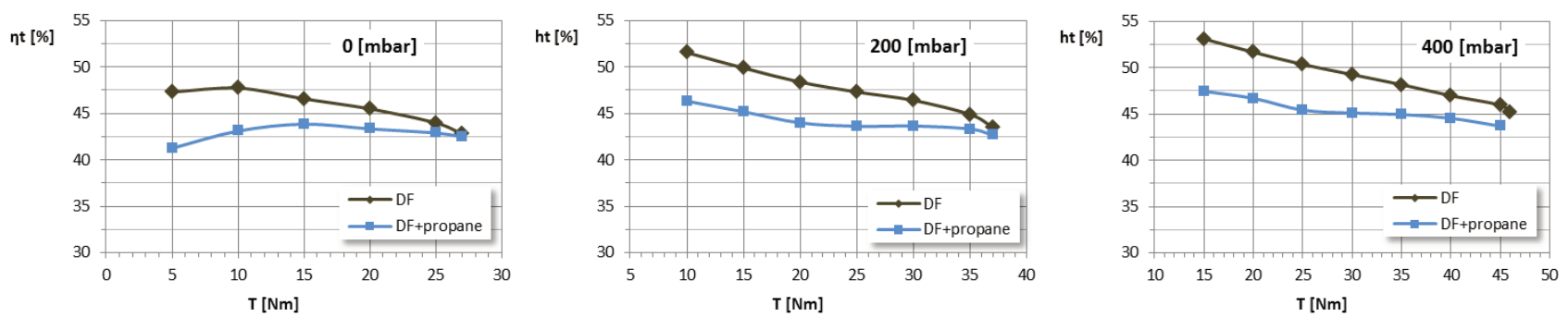

Fig. 2. Load characteristics of thermal efficiency for investigated engine versions
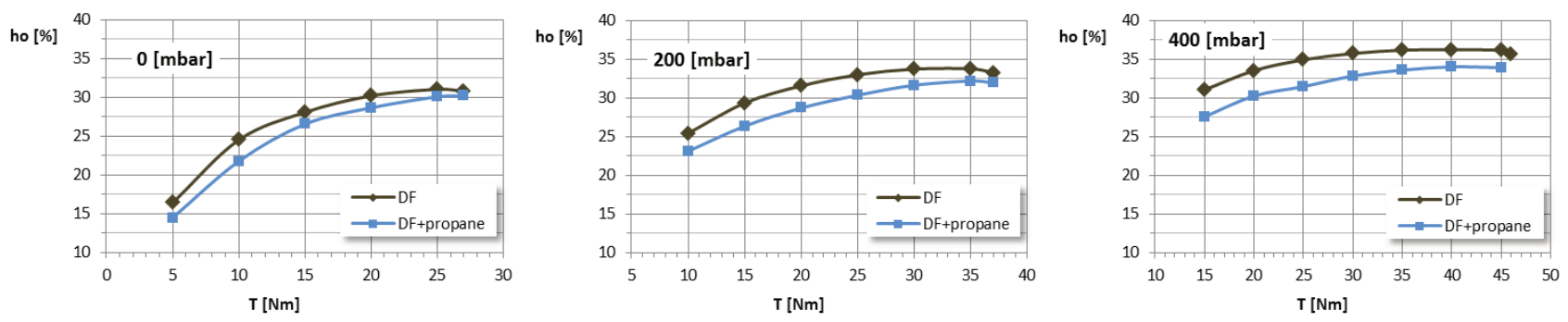

Fig. 3. Load characteristics of overall efficiency for investigated engine versions 
Analysis of propane concentration in the exhaust gas leads to the following observation: propane concentration in the exhaust gas increases with load, reaches maximum at ca. $70 \%$ of the maximum load and then decreases. It should be noticed that the presence of propane in the exhaust gas results from fuel escape during the valve overlap as well as form the effect of incomplete combustion of this fuel (mainly in the area outside the diesel fuel spray for partial loads when the lean air-propane mixture does not undergo combustion). Increase of propane concentration in the exhaust gas of dual-fuel engine with load up to ca. $70 \%$ of the maximum load results from an occurrence of both described above phenomena. Slowing down this process for loads higher than $70 \%$ of the maximum load results from propane escape during the valve overlap period and better combustion with reaching the air-propane mixture (reduc- tion of the incomplete combustion) [8]. The results presented in Fig. 4 allow to state that the dual-fuel engine reaches the same maximum torque as the engine operating in the conventional way for all applied boost pressures.

\section{Results of investigation on the effect of boost pressure on some exhaust emissions from both investigated engine operating modes}

The following emissions have been registered during preparation of load characteristics for both investigated engine operating modes for various boost pressures:

- unburned propane $\mathrm{C}_{3} \mathrm{H}_{8}$,

- particulate matter PM,

- nitrogen oxides $\mathrm{NO}_{\mathrm{x}}$

- non-methane hydrocarbons NMHC.

The results are presented in Figs 4, 5, 6 and 7 respectively.
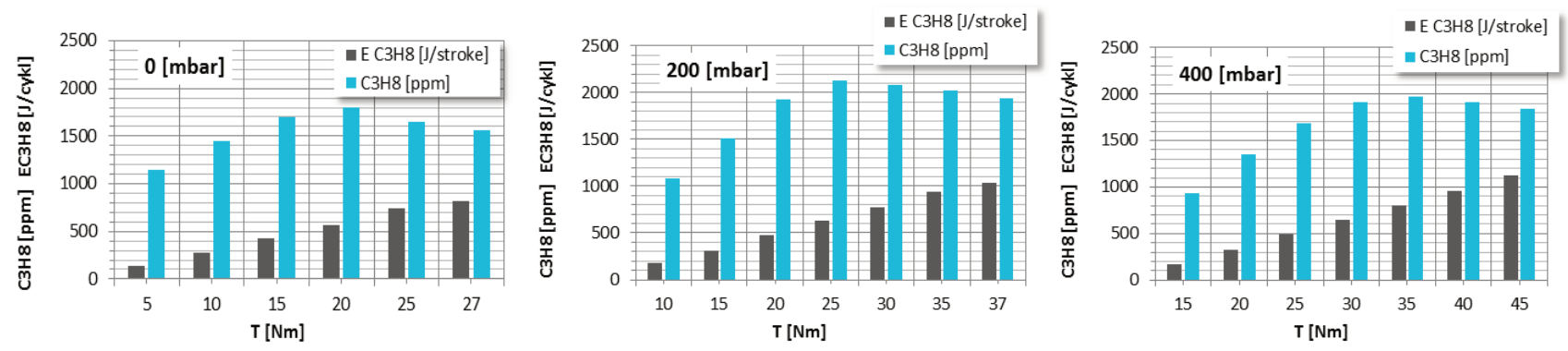

Fig. 4. Load characteristics of unburned propane $(\mathrm{C} 3 \mathrm{H} 8)$ concentration in the exhaust gas for both investigated engine operating modes
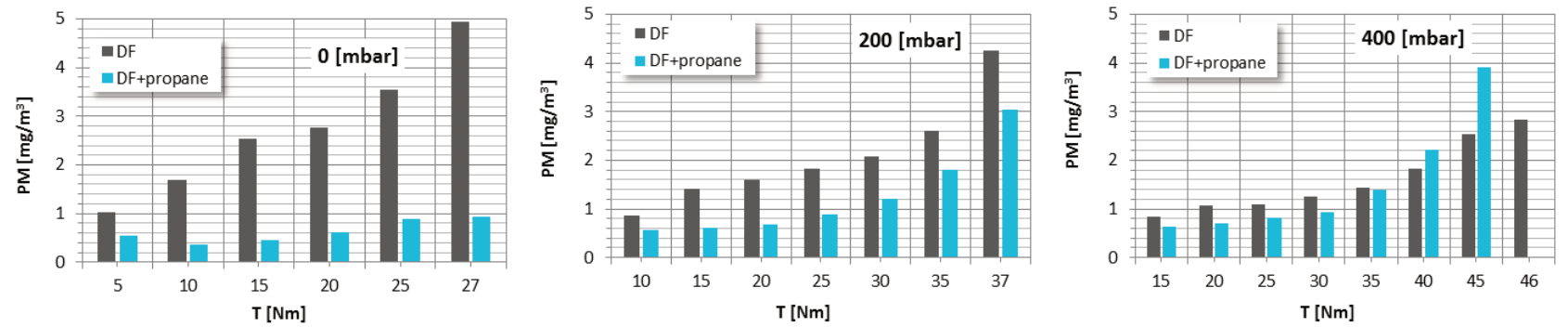

Fig. 5. Load characteristics of particulate matter (PM)concentration in the exhaust gas for both investigated engine operating modes
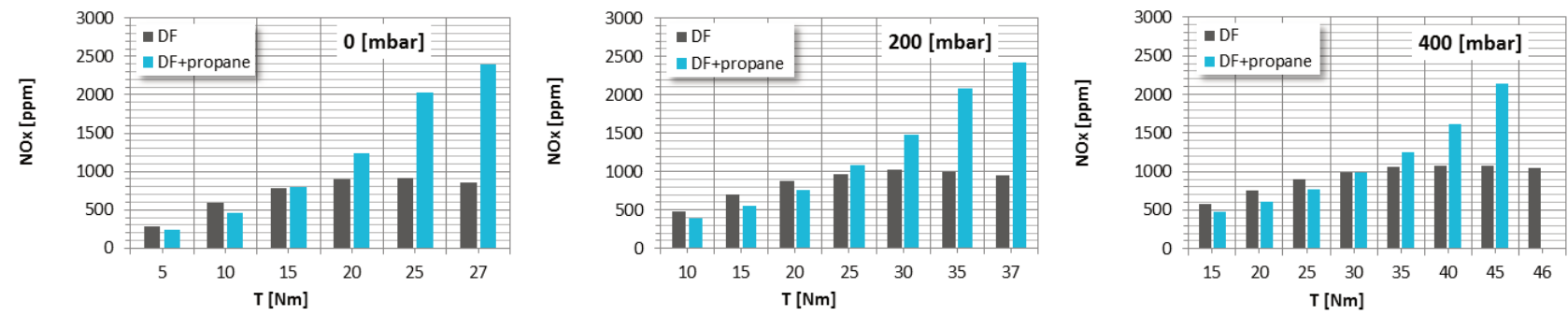

Fig. 6. Load characteristics of nitrogen oxides (NOx) concentration in the exhaust gas for both investigated engine operating modes
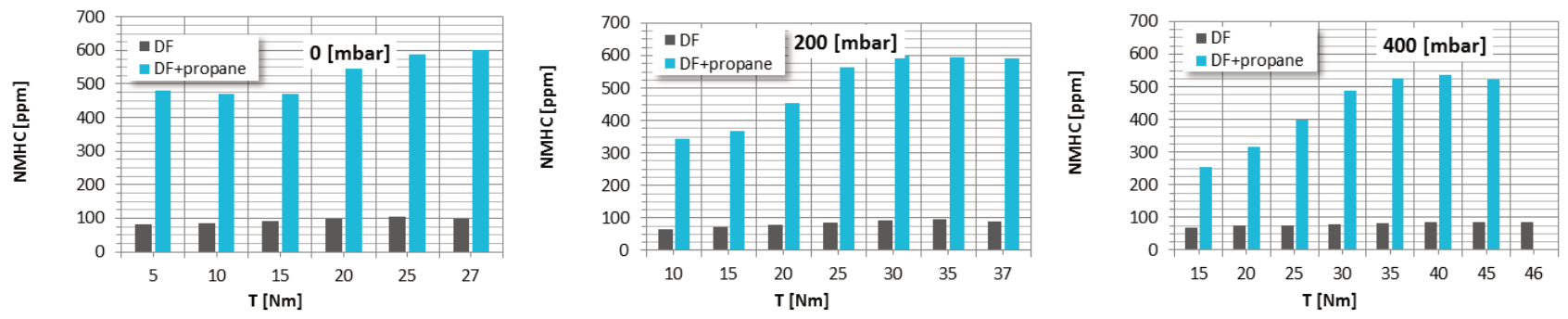

Fig. 7. Load characteristics of non-methane hydrocarbons (NMHC) concentration in the exhaust gas for both investigated engine operating modes 
Analysis of characteristics presented in Figs 4, 5, 6 and 7 leads to the following remarks:

- presence of propane in the exhaust gas results from imposing of two phenomena: escape of a part of the propane charge into the exhaust manifold during the valve overlap and incomplete combustion of the airpropane mixture. Clarification of the course of propane concentration characteristic is described in the $3^{\text {rd }}$ paragraph concerning overall and thermal efficiencies of both investigated engine operating modes,

- nitrogen oxides emission from dual-fuel engine is comparable with emission from conventionally operating engine in the range of low load for all applied boost pressures. In the range of load close to the maximum ones, a visible increase of this emission is observed from dual-fuel engine compared with the standard engine version. It results from higher obtained maximum pressures and thus higher combustion temperatures in dual-fuel engine in this range of load,

- non-methane hydrocarbons emission from dual-fuel engine is visibly higher than from conventionally operating engine in the whole range of load and for all applied boost pressures. It seems that increase of nonmethane hydrocarbons emission from dual-fuel engine results mainly from the fact that diesel fuel combustion deteriorates. It should be remembered that the access to air is reduced when a diesel fuel charge in being injected into the air-propane mixture in this engine version.

- the observed increase of smoke emission from conventionally operating engine in proportion to the engine load is an effect well known and described in the literature $[1,3,4]$. Dual fuel operation, particularly in the case of considerable share of gaseous fuel should be characterized by visible reduction of that emission, what has been confirmed in many tests and has been observed for the investigated engine version but only without turbocharging (boost pressure equal to $0 \mathrm{mbar}$ ) and at the boost pressure of 200 mbar. The described differences in favour of dual-fuel engine are not observed just for the boost pressure of $400 \mathrm{mbar}$, whereas at maximum loads particulate matter emission from that engine is visibly higher than from conventionally operating engine. This may be explained referring to the phenomenon of pyrolysis. Probably, a considerable part of emitted particulate matter originates from the main diesel fuel charge injected into that part of the combustion chamber where combustion process is advanced. Injected diesel fuel particles are in the area with significantly reduced oxygen concentration as a result of combustion initiated by the pilot fuel dose as well as in effect of riching the air-gaseous fuel mixture with engine load. Diesel fuel particles injected in such conditions undergo coking and soot formation as a result of pyrolysis of hydrocarbons. In an injection system of the common rail type, the phenomenon favoring formation of particulate matter may be reduced mainly by delaying the start of injection of the main fuel charge. It will allow mixing the fuel charge in the combustion chamber, thus, better access to air. Moreover, significant delay of the start of injection of the main fuel charge will cause that the combustion chamber pressure in the moment of injection will be lower what, in effect, may result in better spraying and, in this way, better oxidation.

\section{Results of investigation on the effect of boost pressure on basic operating parameters for both investigated engine operating modes}

During preparation of load characteristics for both investigated engine operating modes there were registered combustion pressure courses for the applied boost pressures (Fig. 7). The registered courses served to calculate variability of maximum rate of pressure rise $(\mathrm{dP} / \mathrm{d} \alpha)_{\max }$. (Fig. 8) and crank angle position at burning-out $50 \%$ of the fuel charge (Fig. 9).
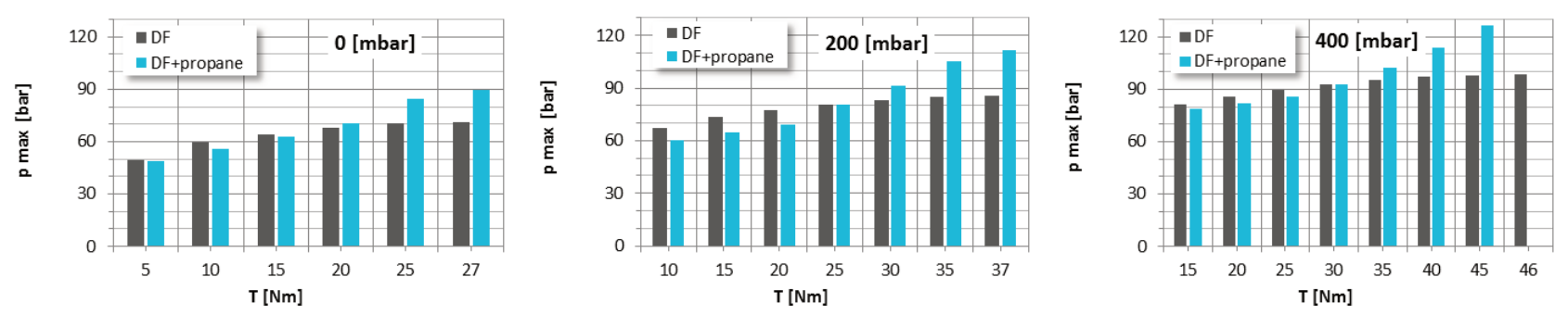

Fig. 8. Load characteristics of maximum combustion pressure courses pmax for both investigated engine operating modes
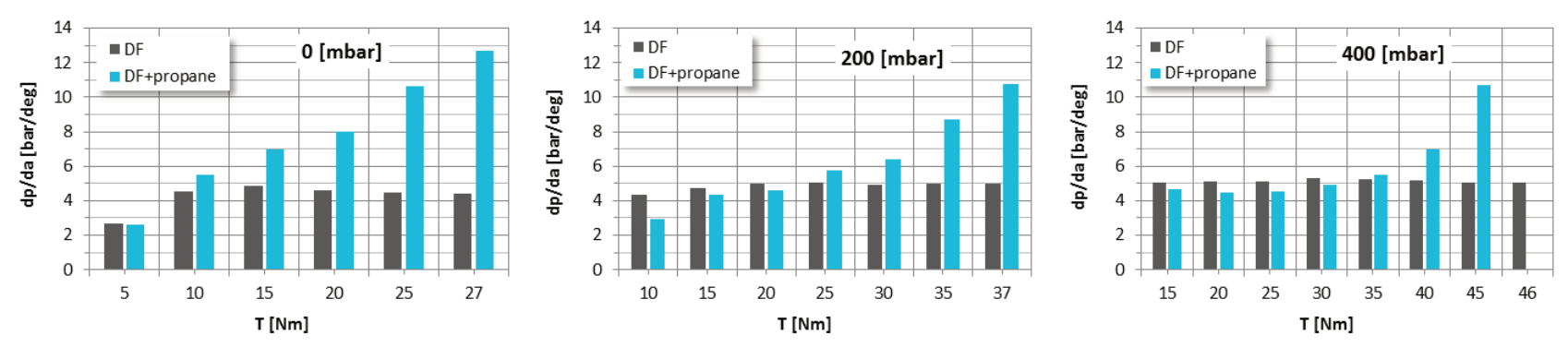

Fig. 9. Load characteristics of maximum rate of pressure rise $(\mathrm{dp} / \mathrm{d} \alpha)_{\max }$ for both investigated engine operating modes 

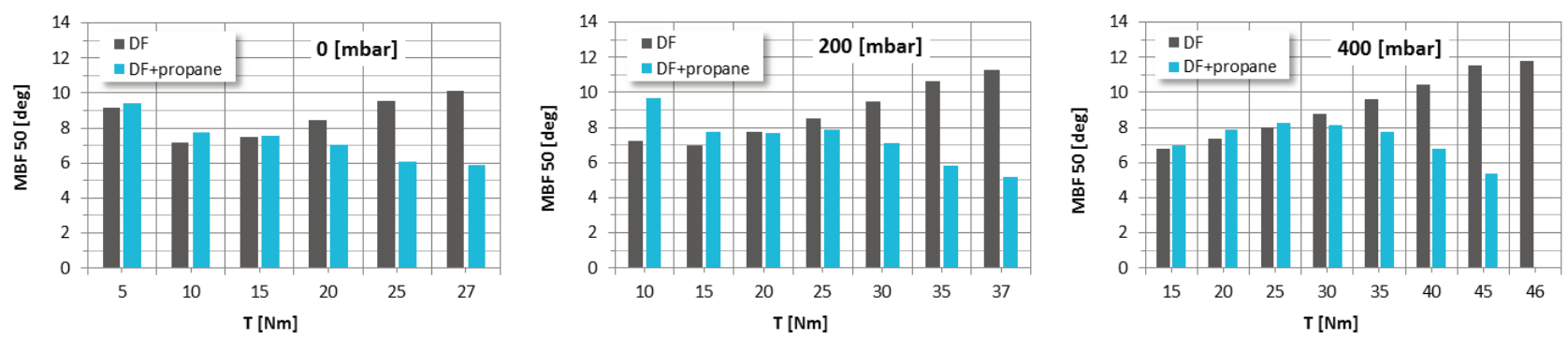

Fig. 10. Load characteristics of crank angle position at burning-out $50 \%$ of the fuel charge for both investigated engine operating modes
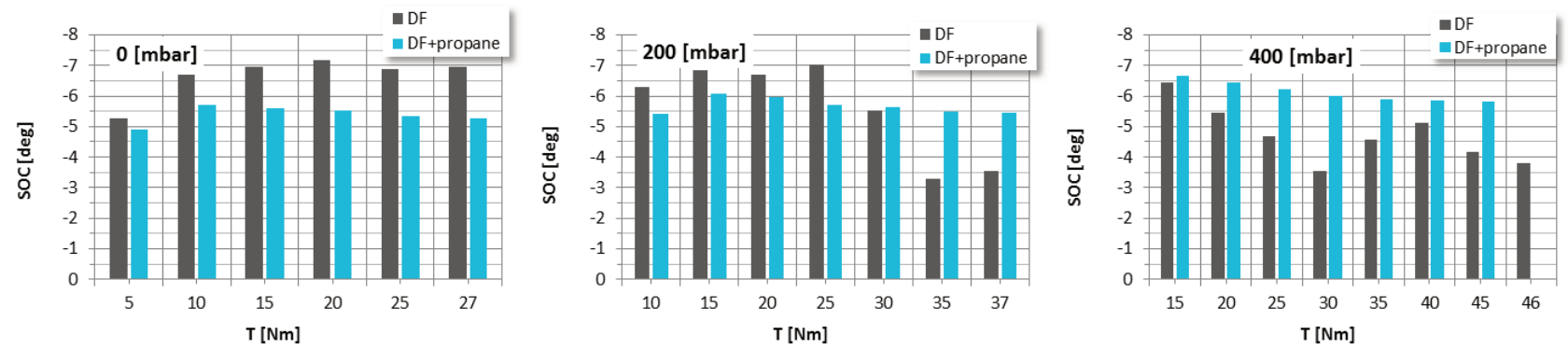

Fig. 11. Load characteristics of crank angle position at the start of combustion (C.A., BTDC) for both investigated engine operating modes

Analysis of maximum combustion pressure courses for both investigated engine operating modes indicates that in the range of partial loads, values of this parameter are comparable for all boost pressure values. In the range of loads close to the maximum ones values of this parameter are higher for dualfuel operation. This is a result of higher rate of pressure rise in dual-fuel engine (particularly visible in the range of maximum loads, Fig. 8). This phenomenon leads to earlier burning-out $50 \%$ of the fuel charge (Fig. 9) at the crank angle position close to TDC. Therefore, intensive combustion occurs in small volume of the chamber and results in the observed increase of maximum combustion pressure. The observed phenomenon suggests that a different regulation of diesel fuel injection parameters should be applied in dual-fuel engine than in conventionally operating engine [2, 5, 7, 9-12]. Additionally, a proper selection of such regulation is justified by the fact that there are differences between ignition delay times and related to this - crank angle position at the start of combustion, what can be seen in Fig. 10.

\section{Summary}

Turbocharged dual-fuel engine compared to conventionally operating engine is characterized by:

- comparable obtained torque for all applied boost pressure values,
- slightly reduced value of overall efficiency for all applied boost pressure values,

- reduced particulate matter PM emission for lower boost pressure values and comparable emission for higher boost pressure values 400 mbar,

- increased nitrogen oxides $\mathrm{NO}_{\mathrm{x}}$ emission for all applied boost pressure values,

- increased non-methane hydrocarbons NMHC emission for all applied boost pressure values,

- visibly increased maximum rates of pressure rise in the combustion process in the range of loads close to the maximum ones for all applied boost pressure values,

- 20-25\% increase of maximum combustion pressure in the range of maximum loads for all applied boost pressure values.

The observed relationships have been obtained at $70 \%-$ $75 \%$ energy share of propane in total energy amount delivered by both fuels. Some improvement, i.e. reduction of maximum pressures and in effect - maximum temperatures in the combustion process may be obtained introducing a change in diesel fuel injection parameters, what should result in reduction of nitrogen oxides $\mathrm{NO}_{\mathrm{x}}$ emission from dual-fuel engine.

\section{Nomenclature}

CI compression ignition

LPG liquified petrolum gas

DF diesel fuel
TDC top dead center

SOC start of combustion

MBF mass burned fraction

\section{Bibliography}

[1] LEE, J., CHOI, S., KIM, H. et al. Reduction of emissions with propane addition to a diesel engine. Int. J. Automotive Technol. 2013, 14(4), 551-558.
[2] LIU, J., YANG, F., WANG, H. et al. Effects of pilot fuel quantity on the emissions characteristics of a $\mathrm{CNG} /$ diesel dual fuel engine with optimized pilot injection timing, Applied Energy. 2013, 110, 201-206. 
[3] LUFT, S. Analysis of combustion process in a dual-fuel compression ignition engine fuelled with LPG in liquid phase. J. KONES Power Train Transp. 2007, 14(4).

[4] OGAWA, H., ZHAO, P., KATO, T., SHIBATA, G. Improvement of combustion and emissions in a dual fuel compression ignition engine with natural gas as the main fuel. SAE Technical Paper. 2015, 2015-01-0863.

[5] PAPAGIANNAKIS, R.G., HOUNTALAS, D.T. Theoretical study of the effects of pilot fuel quantity and its injection timing on the performance and emissions of a dual fuel diesel engine. Energy Convers. Manage. 2007, 48, 2951-2961.

[6] RÓŻYCKI, A. Analysis of performances of a dual-fuel turbocharged compression ignition engine. Journal of KONES Powertrain and Transport. 2010, 17(3).

[7] SAYIN, C, CANAKCI, M. Effects of injection timing on the engine performance and exhaust emissions of a dual-fuel diesel engine. Energy Conversion and Management. 2009, 50.

[8] SKRZEK, T. Assessment of the effect of gaseous fuel delivery mode on thermal efficiency and fuel losses during the

Sławomir Luft, DSc., DEng. - Mechanical Engineering Faculty at Radom University of Technology and Humanities.

e-mail: S.Luft@uthrad.pl valve overlap period in a dual-fuel compression ignition engine. IOP Conf. Series: Materials Science and Engineering. 2016, 148, 012086.

[9] SKRZEK, T. Effect of the diesel fuel dose division and the injection angle on operating parameters of a dual-fuel compression ignition engine. Combustion Engines. 2015, 162(3), PTNSS-2015-3480.

[10] STELMASIAK, Z., MATYJASIK, M. Exhaust emissions of dual fuel self-ignition engine with divided initial dose. Combustion Engines. 2013, 154(3), 144.

[11] STELMASIAK, Z., The combustion controlling in the dual fuel CI engine by pilot dose division. Combustion Engines. 2011, 146(3).

[12] WIERZBICKI, S. Effect of the parameters of pilot dose injection in a dual fuel diesel engine on the combustion process. Journal of KONES Powertrain and Transport. 2011, 18(3), 499-506.

Tomasz Skrzek, DEng., - Mechanical Engineering Faculty at Radom University of Technology and Humanities.

e-mail:T.Skrzek@uthrad.pl 